\title{
Effect of nitrogen, phosphorus and potassium deficiencies on some morphological and physiological properties and nutrient uptake by two almond rootstocks
}

\author{
Abbas Mirsoleimani ${ }^{1, *}$,Mahdi Najafi-Ghiri ${ }^{2}$, Hossein Heydari', \\ Sara Farokhzadeh ${ }^{1}$
}

${ }^{1}$ Department of Plant Production, Faculty of Agriculture and Natural Resources of Darab, Shiraz University, Shiraz, Iran
${ }^{2}$ Department of Soil Science, Faculty of Agriculture and Natural Resources of Darab, Shiraz University, Shiraz, Iran

\begin{abstract}
A soilless culture and completely randomised two-factorial experiment was carried out to investigate the effect of nitrogen $(\mathrm{N})$, phosphorus $(\mathrm{P})$ and potassium $(\mathrm{K})$ deficiencies on macronutrient uptake and to determine some characteristics of Prunus dulcis L. (bitter almond: BA) and Prunus scoparia L. (Alook: AL) seedlings. Seedlings in pots containing perlite were irrigated with half-strength, N-, P- and K-free Hoagland solutions for 12 wk. Results showed that $\mathrm{N}$ deficiency decreased the $\mathrm{N}$ and $\mathrm{Ca}$ levels and increased the $\mathrm{K}$ concentration in the shoots of both rootstocks. Phosphorus deficiency decreased $\mathrm{N}$ and $\mathrm{P}$ concentrations of both seedlings, as well as the $\mathrm{Ca}$ and $\mathrm{Mg}$ concentrations of BA seedlings. Potassium deficiency decreased the $\mathrm{K}$ concentration of the BA seedlings and decreased N, K and $\mathrm{Ca}$ concentrations of the AL seedlings. In the BA seedlings, only the fresh weight of the shoot decreased under the $\mathrm{P}$ deficiency condition; the other morphological traits of shoots in this genotype and none of the traits in the AL seedlings were affected by P deficiency. Furthermore, both the rootstocks can maintain their optimal growth even at very low concentration of $\mathrm{K}$; this shows that both rootstocks consume $\mathrm{K}$ in a luxurious way. Under nutrient-deficient conditions, the $\mathrm{AL}$ seedling has greater ability to maintain the $\mathrm{N}$ concentration or uptake it more than the BA seedling. The N P and K deficiency conditions disturbed the electron transfer cycle of photosystem II in the AL leaves and caused a response. Most root traits of the AL seedling were not changed under nutrient deficiency, and this indicates a high tolerance of the AL roots compared to the BA roots or lower demand in this genotype for these elements. The characteristics of $P$. scoparia seedlings were less affected by the deficiency of these three elements, and therefore, $P$. scoparia rootstock is preferred to BA for weak and non-fertile soils.
\end{abstract}

Keywords: bitter almond, chlorophyll florescence, K deficiency, N deficiency, P deficiency, Prunus scoparia

Abbreviations: AL, Alook (Prunus scoparia L.); BA, bitter almond (Prunus dulcis; syn. P. amygdalus, Amygdalus communis L.); $F_{0}$, initial fluorescence; $F_{\mathrm{m}}$, maximum fluorescence; $F_{\mathrm{v}}$, variable fluorescence; PS II, photosystem II; RWR, root weight ratio; SLA, specific leaf area; SLW, specific leaf weight; SRL, specific root length.

\section{INTRODUCTION}

Iran is one of the sources of germplasm for domestic and wild fruit tree species such as Prunus (Mozaffarian,
1996). The widespread adaptation of the species of this genus, especially wild almonds, indicates their high 
potential as a source of resistance to biotic and abiotic stresses, and thus these plants provide a valuable source of germplasm for breeding purposes (Gradziel et al., 2001). The use of wild almond species as a rootstock in Iran can be traced back to about $300 \mathrm{y}$ ago (Madam et al., 2011).

For better use of this genetic diversity in breeding programmes and as rootstock, it is necessary to conduct research on this germplasm to determine the valuable agronomic, morphological and physiological characteristics, as well as the resistances and sensitivities of this species. Research has shown that changes in the root's morphological characteristics, such as surface area and length, are essential for soil exploration and access to subsurface resources by the plant; therefore, these root characteristics have a strong relationship with a plant's adaptation to nutrient-deficiency conditions, such as lack of nitrogen $(\mathrm{N})$, phosphorus $(\mathrm{P})$ and boron, as well as other biotic stresses (López-Bucio et al., 2003; Yan et al., 2004; Desnos, 2008; Mei et al., 2011; Trubat et al., 2012).

Prunus scoparia L. (Alook) (AL) is one of the wild almond species native to Iran, and it grows as a large shrub with green and elongated shoots in many parts of this country. Shrubs of this species are used in arid and semi-arid regions to prevent soil erosion. The seedlings of this shrub are used as a rootstock for different almond cultivars due to their high tolerance to abiotic stresses, such as drought, salinity, low soil fertility and low winter temperatures; moreover, they are considered as important sources in almond breeding programmes (Gharaghani and Eshghi, 2014). As rootstocks, AL seedlings show high grafting success, extensive root systems and vigorous shoot growth (Madam et al., 2011). Bitter almond (BA) (Amygdalus communis L.) grows in the wild and can be used as a rootstock for some stone fruits, especially almonds and peaches. This genotype grows in marginal and arid regions and, therefore, it can be expected to be resistant to drought and salinity (Shibli et al., 1998, 1999). Despite its many useful properties and its wide use as a rootstock in Iran, no comprehensive research has been done so far on the mechanisms of its high tolerance to biotic and abiotic stresses.

In breeding programmes, identifying more-efficient genotypes in terms of nutrient uptake based on the morphological characteristics of the root and the shoot is an important step towards solving the problem of nutrient deficiency in the soil. In order to select appropriate rootstocks, it is necessary to have an accurate understanding of the morphological, physiological and anatomical reactions of different genotypes to nutrient deficiency conditions and to determine the critical level of stress and the type of reaction of each genotype in the absence of that element.

It is assumed that different almond rootstocks show different reactions to nutrient deficiencies and, therefore, can differ in terms of resistance to such stresses. Due to the lack of enough information about the effect of nutrient deficiency on morphological and physiological reactions of almond rootstocks, the aims of this study were to compare the morphological and physiological reactions of $A$. communis $\mathrm{L}$. and $P$. scoparia L. rootstocks and to determine the resistance or tolerance of each rootstock to N, P and K deficiency conditions.

\section{MATERIALS AND METHODS}

\section{Site of the experiment}

The experiment was carried out in 2019 from January to April in a greenhouse with $28{ }^{\circ} \mathrm{C}$ day $/ 20{ }^{\circ} \mathrm{C}$ night, a 12 -h photoperiod and relative humidity between $50 \%$ and $65 \%$ under natural sunlight condition at the College of Agriculture and Natural Resources of Darab, Shiraz University, Fars Province, Iran.

\section{Plant materials and culture conditions}

Mature seeds of BA (Prunus dulcis; syn. P. amygdalus, Amygdalus communis L.) and AL (P. scoparia; syn. Amygdalus scoparia) were collected from openpollinated mother trees; their hard shells were broken and healthy, uniform seeds were soaked in distilled water for $24 \mathrm{~h}$. Seeds were surface-sterilised in 5\% (v/v) sodium hypochlorite solution for $15 \mathrm{~min}$ and rinsed with water. The seeds were then placed in a sterile perlite medium in a refrigerator at $4{ }^{\circ} \mathrm{C}$ for $30 \mathrm{~d}$ for stratification. After stratification, three germinated seeds were transferred to each pot ( $25 \mathrm{~cm}$ diameter) containing perlite. In order to establish the plants, the pots were first irrigated with distilled water for $3 \mathrm{wk}$ and then with Hoagland nutrient solution (Hoagland and Arnon, 1950) (Table 1) for $10 \mathrm{~d}$. In order to apply the treatments, the seedlings were irrigated for $12 \mathrm{wk}$, three times a week, and each time with $200 \mathrm{~mL}$ of the desired nutrient solutions. Control treatment was included using half-strength Hoagland nutrient solution (Table 1) and N-, P- and K-free nutrient solutions were prepared as follows: $\mathrm{N}$-free medium $\left(\mathrm{CaCl}_{2}, 2 \mathrm{mM} ; \mathrm{K}_{2} \mathrm{SO}_{4}, 1.5 \mathrm{mM} ; \mathrm{KH}_{2} \mathrm{PO}_{4}, 0.5 \mathrm{mM}\right)$; P-free medium $\left(\left(\mathrm{NH}_{4}\right)_{2} \mathrm{SO}_{4}, 0.25 \mathrm{mM}\right)$; and $\mathrm{K}$-free medium $\left(\mathrm{NaNO}_{3}, 3 \mathrm{mM} ; \mathrm{NH}_{4} \mathrm{H}_{2} \mathrm{PO}_{4}, 0.5 \mathrm{mM}\right)$. In all solutions, $0.1 \mathrm{M} \mathrm{NaOH}$ was used to adjust the $\mathrm{pH}$ to 6.0 .

Table 1. Composition of nutrient solutions used in the experiments.

\begin{tabular}{lll}
\hline Parameter & Composition & Concentration \\
\hline Macronutrients & $\mathrm{Ca}\left(\mathrm{NO}_{3}\right)_{2} \cdot 4 \mathrm{H}_{2} \mathrm{O}$ & $2 \mathrm{mM}$ \\
& $\mathrm{KNO}_{3}$ & $3 \mathrm{mM}$ \\
& $\mathrm{MgSO}_{4} \cdot 7 \mathrm{H}_{2} \mathrm{O}$ & $1 \mathrm{mM}$ \\
& $\mathrm{NH}_{4} \mathrm{H}_{2} \mathrm{PO}_{4}$ & $0.5 \mathrm{mM}$ \\
\hline Micronutrients & $\mathrm{H}_{3} \mathrm{BO}_{3}$ & $46 \mu \mathrm{M}$ \\
& $\mathrm{MnSO}_{4} \cdot \mathrm{H}_{2} \mathrm{O}$ & $9.2 \mu \mathrm{M}$ \\
& $\mathrm{ZnSO}_{4} \cdot 7 \mathrm{H}_{2} \mathrm{O}$ & $0.77 \mu \mathrm{M}$ \\
& $\mathrm{CuSO}_{4} \cdot 5 \mathrm{H}_{2} \mathrm{O}$ & $0.32 \mu \mathrm{M}$ \\
& $\mathrm{H}_{2} \mathrm{MoO}_{4}$ & $0.12 \mu \mathrm{M}$ \\
& EDTA-Fe & $50 \mu \mathrm{M}$ \\
\hline
\end{tabular}


After every $3 \mathrm{wk}$ of irrigation with nutrient solution, the pots were irrigated with distilled water so that the culture medium was completely washed.

\section{Leaf chlorophyll, chlorophyll fluorescence parameters and SPAD determination}

At the end of the experiment, the greenness of fully expanded young leaves was determined using the leaf chlorophyll meter SPAD-502 (Minolta, Osaka, Japan), and the chlorophyll fluorescence parameters were determined using a manual chlorophyll meter (OS30P; Opti-Sciences Co., Hudson, NH, USA). For determination of the fluorescence parameters, leaves were acclimated to the dark for $20 \mathrm{~min}$ by placing a clamp on them, before measurements were taken. Then, chlorophyll fluorescence parameters, including the initial fluorescence $\left(F_{0}\right)$, maximum fluorescence $\left(F_{\mathrm{m}}\right)$, variable fluorescence $\left(F_{\mathrm{v}}\right)$, and $F_{\mathrm{v}} / F_{\mathrm{m}}$ were recorded; then, $F_{\mathrm{v}} / F_{0}$ was calculated. To determine the leaf chlorophyll concentration, four young, fully expanded leaves were taken from each seedling and kept in the freezer at $-30{ }^{\circ} \mathrm{C}$; then, $50 \mathrm{mg}$ of frizzed ground leaf tissue was extracted with methanol and the absorbance of the extract was determined using a microplate reader (Synergy 2; BioTek, Winooski, VT, USA) at wavelengths of 652 and $665 \mathrm{~nm}$ (Warren, 2008).

\section{Determination of morphological traits of the shoot}

At the end of the experiment, 10 leaves were randomly selected from each seedling, and their area was determined using a leaf area meter (Delta-T Scan; Delta-T Devices, Burwell, Cambridge, England) using the WinDIAS3 software. Then the plants were transferred to the laboratory, and the shoots were cut from the crown; traits such as the length of the main branch (plant height) and the fresh and dry weights of the shoots were measured. Specific leaf area (SLA) index was calculated by dividing the obtained area by the dry weight of the leaf; the specific leaf weight (SLW) index was calculated by dividing the dry weight of the leaf by the leaf area.

\section{Determination of morphological traits of the root}

The roots were then removed from the pots intact, washed and put on a flat screen, and the image of the root system was taken using a digital camera (EOS 600D; Canon, Tokyo, Japan). The obtained images were analysed using GiaRoot software, and traits such as length, diameter, volume, surface area, circumference, specific root length (SRL: root length/root dry weight) and root weight ratio (RWR: root dry weight/plant dry weight) were determined. After measuring the fresh weight of the roots with a digital scale, the roots were placed at $70^{\circ} \mathrm{C}$ for $48 \mathrm{~h}$, and then the dry weight of the roots was determined.

\section{Plant mineral analysis}

Shoots and roots were harvested separately and were dried at $70{ }^{\circ} \mathrm{C}$ until constant weight was reached. After grinding, $0.5 \mathrm{~g}$ of each sample was ashed at $550{ }^{\circ} \mathrm{C}$ for $5 \mathrm{~h}$ and digested with $5 \mathrm{~mL}$ of $2 \mathrm{M}$ hydrochloric acid. In the obtained extract, the concentrations of $\mathrm{K}, \mathrm{Ca}$ and $\mathrm{Mg}$ were measured with a flame photometer (Model 405; Corning, Halstead Essex, UK), and the concentration of $\mathrm{P}$ was measured with a spectrophotometer (UV-1800; Shimadzu, Kyoto, Japan) at $460 \mathrm{~nm}$ (Jackson, 2005). Nitrogen was determined by the micro-Kjeldahl method in the ground samples of the root and shoot (Bremner, 1996).

\section{Statistical analysis}

The experiment was established in a completely randomised two-factorial design with two rootstocks (BA and $\mathrm{AL}$ ) and four nutrient solutions: complete solution (control), without $\mathrm{N}(-\mathrm{N})$, without $\mathrm{P}(-\mathrm{P})$ and without $\mathrm{K}(-\mathrm{K})$, with four replications; each replication includes a pot containing three seedlings. Statistical analysis of the data was performed using the SPSS and SAS statistical packages, and the differences were statistically compared based on the least significant difference (LSD) at the 0.01 level of probability.

\section{RESULTS AND DISCUSSION}

\section{Concentration of nutrients in the shoot}

The concentration of $\mathrm{N}$ in the BA seedling shoots was lower than that in the AL shoots both under optimal conditions and in the absence of $\mathrm{N}, \mathrm{P}$ and $\mathrm{K}$ (means of 1.33 vs. 1.68\%) (Figure 1A). Moreover, N and $\mathrm{P}$ deficiencies caused a significant decrease in $\mathrm{N}$ concentration in the shoots of the BA seedlings compared to the result under optimal conditions, while $\mathrm{K}$ deficiency had no effect on it. In the AL seedlings, N, $\mathrm{P}$ and $\mathrm{K}$ deficiency conditions significantly reduced the $\mathrm{N}$ concentration in the shoot. Comparison of the effect of $\mathrm{N}, \mathrm{P}$ and $\mathrm{K}$ deficiencies on the $\mathrm{N}$ concentration of the two rootstock shoots showed that $\mathrm{N}$ deficiency had a greater effect in terms of reducing the plant $\mathrm{N}$ content (mean of 34\%), while $\mathrm{P}$ and $\mathrm{K}$ deficiencies reduced plant $\mathrm{N}$ by $14 \%$ and $7 \%$, respectively. Phosphorus deficiency can affect the uptake of other elements, including $\mathrm{N}$, through its effects on root characteristics, such as the length and root surface area (Figures $3 \mathrm{C}$ and $3 \mathrm{~F}$ ). While $\mathrm{K}$ is the most important cation taken up by plants, uptake of anions such as nitrate may also be reduced in the K-deficient condition due to the anion-cation balance in the plant. A decrease in the nitrate content in plants due to $\mathrm{K}$ deficiency has also been reported by Hu et al. (2017). They found that the activity of nitrate reductase decreased in the absence of $\mathrm{K}$ in the plant, and as a result, the $\mathrm{C}: \mathrm{N}$ ratio was increased. On the other hand, $\mathrm{K}$ ions are often the main cations maintaining the ionic balance in the process of nitrate transfer in the xylem and storage in the vacuoles; therefore, a decrease in $\mathrm{K}$ level in the plant can interfere with nitrate transfer and storage (Marschner, 2011).

In the BA seedlings, the $\mathrm{P}$ concentration in the shoot was affected by $\mathrm{P}$ deficiency, showing a decrease, while $\mathrm{N}$ 

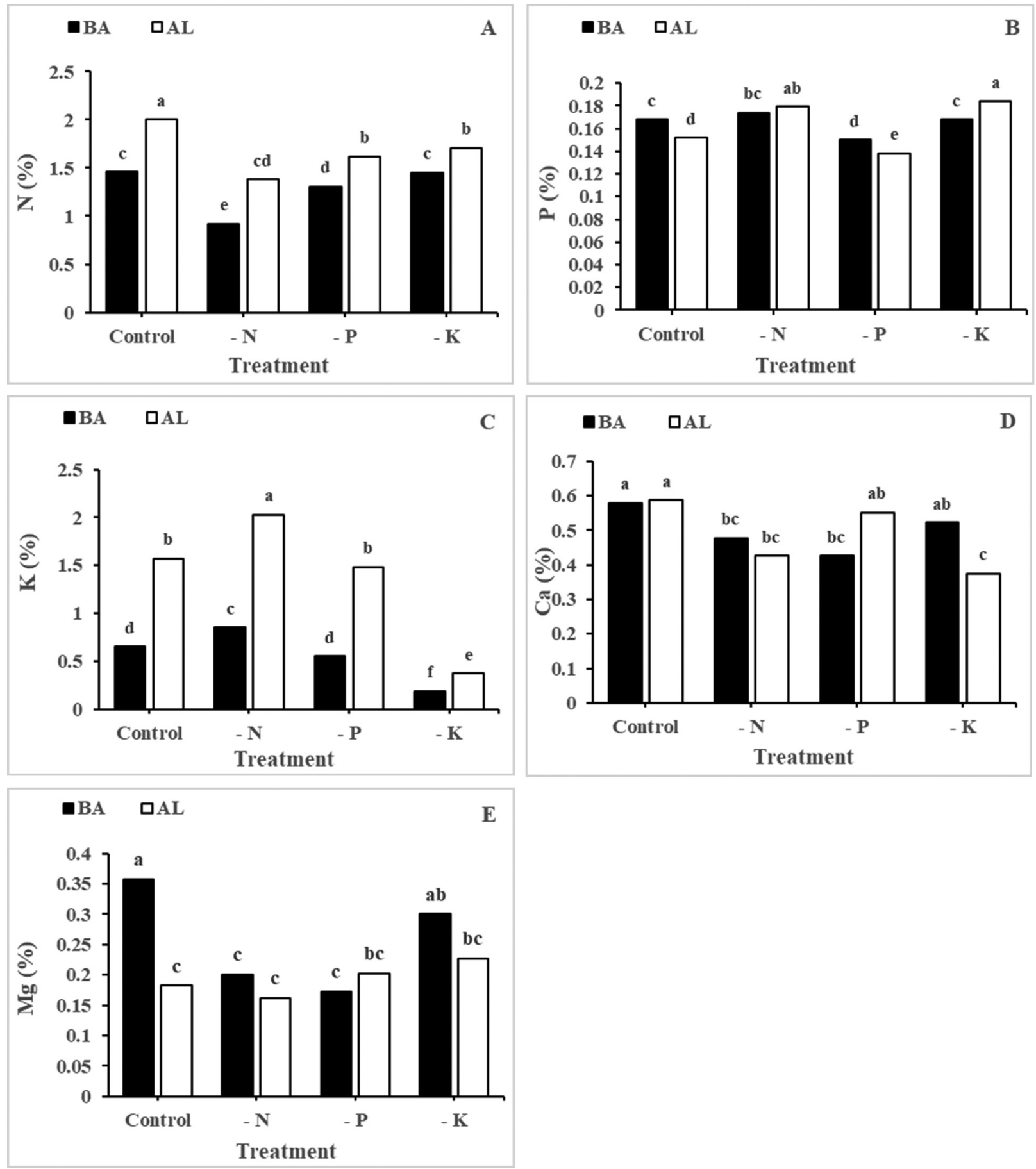

Figure 1. Effects of nutrient deficiency on the shoot macronutrient concentrations in BA and AL seedlings. Different letters indicate statistically significant difference between means $(p<0.05)$. $-\mathrm{N},-\mathrm{P}$ and $-\mathrm{K}$ indicate media without $\mathrm{N}$, P and K, respectively. AL, Alook (Prunus scoparia L.); BA, bitter almond (Prunus dulcis L.).

and $\mathrm{K}$ deficiencies had no effect on it. In the AL seedlings, the shoot $\mathrm{P}$ concentration was increased significantly in the absence of $\mathrm{N}$ and $\mathrm{K}$, while P deficiency decreased it. This increase in $\mathrm{P}$ concentration in the absence of $\mathrm{N}$ and $\mathrm{K}$ can be related to the increase in SLA (Figure 2F) and the reduction in SLW (Figure 2E) in these seedlings and, leading to presence of more concentrated P. Deficiencies of $\mathrm{N}$ and $\mathrm{K}$, respectively, caused a reduction of $26 \%$ and $29 \%$ in the SLW and an increase of $40 \%$ and $40 \%$ in the SLA of the AL seedling (Figure 2E).
The $\mathrm{K}$ concentration in the shoots of the AL seedlings was significantly higher than in the shoots of the BA seedlings (means of $1.36 v s .0 .56 \%$ ) (Figure 1C). Deficiency of $\mathrm{N}$ increased the $\mathrm{K}$ concentration in the shoots of both rootstocks, but $\mathrm{P}$ deficiency had no effect on shoot $\mathrm{K}$ concentration. In the absence of $\mathrm{K}$ in the nutrient solution, the concentration of this element in the shoots of the BA and AL seedlings decreased by $71 \%$ and $76 \%$, respectively. A significant reduction of $\mathrm{K}$ in the aerial parts of the seedlings growing in the $\mathrm{K}$ deficiency condition can 

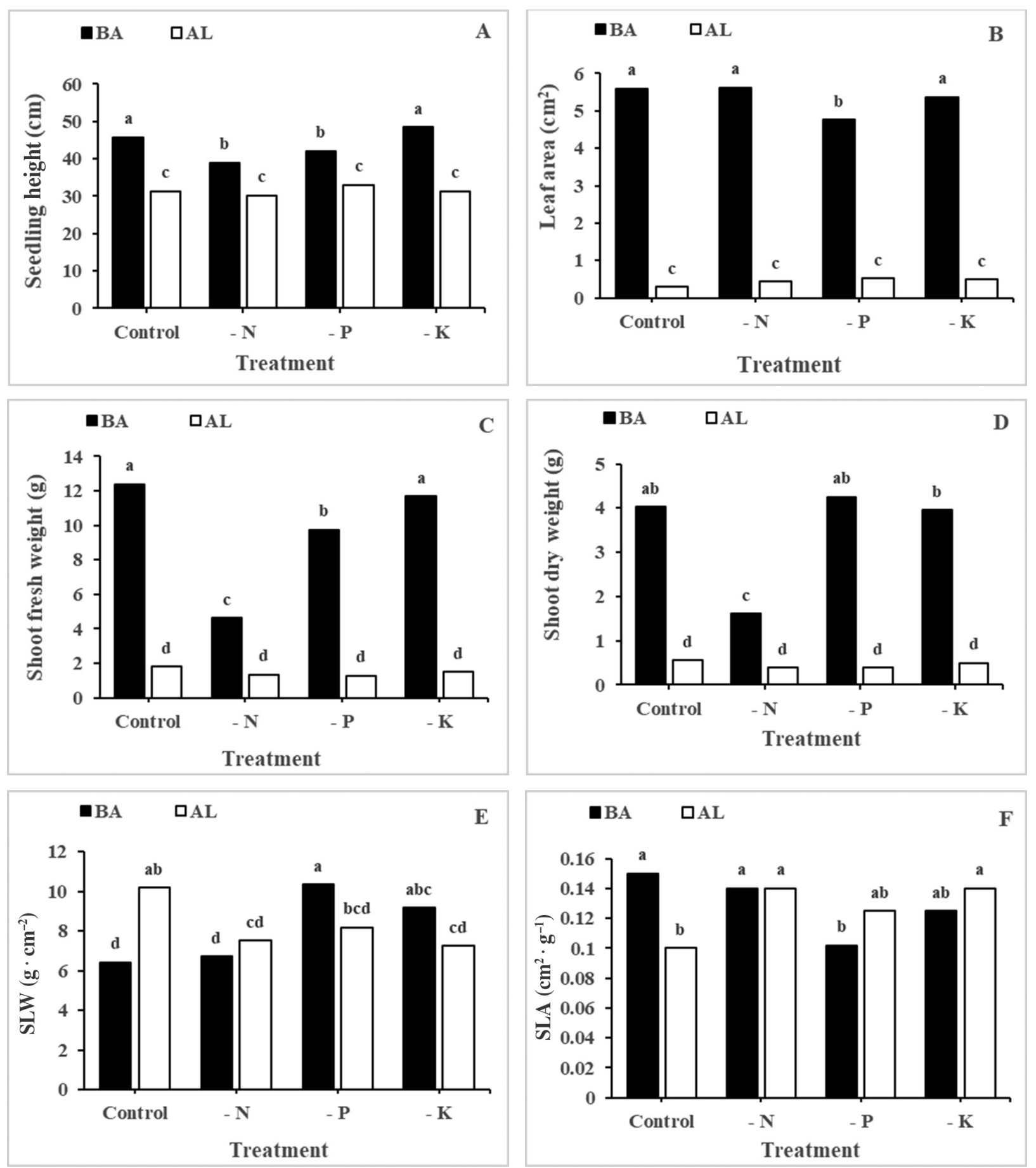

Figure 2. Effects of nutrient deficiency on the morphological traits of the shoots of BA and AL seedlings. Different letters indicate statistically significant difference between means $(p<0.05)$. $-\mathrm{N},-\mathrm{P}$ and $-\mathrm{K}$ indicate media without $\mathrm{N}$, $\mathrm{P}$ and $\mathrm{K}$, respectively. AL, Alook (Prunus scoparia L.); BA, bitter almond (Prunus dulcis L.).

be related to the lower $\mathrm{K}$ uptake and also no significant reduction in shoot dry weight due to the $\mathrm{K}$ deficiency. It means that $\mathrm{K}$ concentration in the plant is not affected by dilution under K-deficient condition.

Deficiencies of $\mathrm{N}$ and $\mathrm{P}$ in the BA seedlings and $\mathrm{N}$ and $\mathrm{K}$ deficiencies in the AL seedlings caused a significant decrease in shoot calcium $(\mathrm{Ca})$ concentration. In the $\mathrm{N}$-deficient condition, due to the fact that the main source of $\mathrm{N}$ in the solution is the nitrate anion, the absorption of cations is also reduced, and the competition between cations such as $\mathrm{Ca}$ and $\mathrm{K}$ is increased. Comparing the concentrations of $\mathrm{K}$ and $\mathrm{Ca}$ in the plant under $\mathrm{N}$-deficient condition, it is found that $\mathrm{K}$ uptake is preferential. In fact, $\mathrm{K}$ is considered the preferred cation for plant anioncation balance and also the preferred cation with nitrate for transfer in plants (Marschner, 2011).

Although deficiency of any element in the $\mathrm{AL}$ seedling had no effect on shoot $\mathrm{Mg}$ concentration, 
in the BA seedling, $\mathrm{N}$ and $\mathrm{P}$ deficiencies caused a significant decrease in shoot $\mathrm{Mg}$ concentration, but $\mathrm{K}$ deficiency had no effect on it. Further, $\mathrm{Mg}$ is strongly influenced by the absorption of other cationic elements, especially K (Marschner, 2011), and since K uptake is increased in the absence of $\mathrm{N}$ and $\mathrm{P}$, it seems that it has a negative effect on $\mathrm{Mg}$ uptake. On the other hand, as is known, in the K deficiency condition, the amount of $\mathrm{Mg}$ absorption is improved. In the $\mathrm{N}$ deficiency condition, the concentrations of $\mathrm{N}, \mathrm{Ca}$ and $\mathrm{Mg}$ are decreased, while the concentrations of $\mathrm{P}$ and $\mathrm{K}$ are increased. This may be due to the reduction in plant growth in $\mathrm{N}$ deficiency condition (dilution effect) or the competition among different cations for adsorption in the low anion-uptake condition (nitrate), with preferential absorption of K. Lower changes in shoot $\mathrm{P}$ concentration in the $\mathrm{P}$ deficiency condition, compared to the control in the two genotypes, indicate the low $\mathrm{P}$ requirement of almond rootstocks. On the other hand, small changes in $\mathrm{P}$ concentration in P-deficient conditions may be related to the high ability of $\mathrm{P}$ to remobilise in the phloem vessels to compensate the demand for $\mathrm{P}$ from new tissues under deficiency conditions (Zambrosi et al., 2012). Remobilisation of the plant's internal $\mathrm{P}$ is one of the most important mechanisms to overcome the temporary deficiency of this element in order to improve the efficiency of $\mathrm{P}$ consumption in the plant (Zambrosi et al., 2012). On the other hand, the lack of $\mathrm{P}$ in the nutrient solution reduces the concentration of $\mathrm{Ca}$ and $\mathrm{Mg}$ in the shoots of the BA seedlings. Moreover, P deficiency in the soil is one of the critical aspects that limits the production and yield of many plants; high or low concentrations of P may stop the absorption of elements such as N, K, $\mathrm{Fe}, \mathrm{Zn}$ and B (Tu et al., 2018). In agreement with these results, Tu et al. (2018) showed that low P application in citrus rootstocks can reduce the concentration of $\mathrm{Mg}$ in the leaves and thus reduce the photosynthetic activity of the leaves, ultimately reducing the dry weight of the plant. Lack of $\mathrm{K}$ in the nutrient solution also reduced the absorption of $\mathrm{N}$ and $\mathrm{K}$ in the plant. In general, it can be concluded that the concentration of shoot $\mathrm{N}$ and $\mathrm{K}$ in the AL seedlings is significantly higher than that in the BA seedlings, but in terms of $\mathrm{P}$ concentration, it depends on the nutritional status of the plant.

\section{Shoot morphological traits}

In the control treatment (which included all nutrients), significant differences in plant height, leaf area and the shoot's fresh and dry weights were observed between the two genotypes so that for all traits, the BA seedlings had higher values than the AL seedlings (Figure 2). Moreover, $\mathrm{N}$ deficiency caused a significant decrease in plant height (Figure 2A), fresh weight and dry weight of the BA seedlings compared to the control treatment, but it had no effect on the leaf area. However, in the AL seedlings, $\mathrm{N}$ deficiency had no significant effect on these traits (Figure 6). Furthermore, P deficiency conditions only caused a significant reduction in shoot fresh weight compared to the control treatment in the BA seedlings but it did not affect other traits in this genotype and no traits in the AL seedlings were affected; this indicates the low $\mathrm{P}$ requirement of plants. Deficiency of $\mathrm{K}$ in the nutrient solution had no significant effect on seedling height, leaf area, shoot fresh and dry weights and the SLW of the two genotypes. In only the AL seedlings, the lack of K in the root environment increased the SLA (Figure 2). In the control treatment, the SLW of the AL seedlings was $34.7 \%$ higher than that of the BA seedlings, while in other treatments, this trait was not significantly different between the two genotypes. The highest SLW of BA seedlings was observed in $\mathrm{P}$ deficiency treatment and although the values of this trait in the control, without $\mathrm{N}$ and without $\mathrm{K}$ treatments were lower than the values without $\mathrm{P}$ treatment, this decrease was significant only in the control and without $\mathrm{N}$ treatments. The SLW of AL leaves was the highest under optimal nutrient conditions and significantly decreased in the $\mathrm{N}$ and $\mathrm{K}$ deficiency treatments (Figure 2E).

Although $\mathrm{K}$ deficiency caused a significant decrease in the $\mathrm{K}$ concentration in the aerial parts of both rootstocks $(>70 \%)$ (Figure 1), it did not affect the plant biomass. Both rootstocks seem to undertake luxury consumption of $\mathrm{K}$ and can maintain their optimal growth even at low concentrations of $\mathrm{K}$. Although $\mathrm{K}$ is involved in the transport of carbon dioxide through the stomata and thus the process of photosynthesis, some researchers (Basile et al., 2003) have shown that almonds can maintain this process even at very low concentrations of $\mathrm{K}$. The reduction in leaf photosynthesis may be due to the effect of $\mathrm{K}$ on other biochemical processes within the plant. In general, the results showed that the lack of $\mathrm{N}$ in the nutrient solution significantly reduced the vegetative growth indices of the BA seedlings except the leaf area, but it had no effect on the vegetative growth of AL seedlings. After C, nitrogen is needed by a plant in large amounts, and sufficient $\mathrm{N}$ must be supplied to achieve proper vegetative and reproductive growth. Nitrogen is a component of proteins, nucleic acids, chlorophyll molecules, coenzymes, phytohormones and some secondary metabolites (Marschner, 2011). This element has the most important role in plant physiological processes and, when present in optimal amounts, it increases photosynthesis, leaf area, leaf longevity and the rate of metabolic processes of plant cells. Deficiency of this element reduces growth, creates chlorosis and stops the growth of lateral buds (Marschner, 2011; Leghari et al., 2016). However, as shown in Figure 1, the amount of $\mathrm{N}$ in the shoots of AL seedlings was significantly higher than that of BA seedlings, even in the absence of $\mathrm{N}$. This means that under the same conditions, the AL seedlings have the ability to maintain $\mathrm{N}$ concentration in their shoots or absorb more $\mathrm{N}$, compared to the BA seedlings, even under nutrient stress conditions. On the other hand, the 
lower biomass of the AL seedlings reduces its need for nutrients, especially $\mathrm{N}$, compared to the BA seedlings. Zarate-Valdez et al. (2015) found that the almond yield is closely related to the amount of leaf $\mathrm{N}$ and is less dependent on factors such as leaf area and light absorption. It has also been shown that $\mathrm{N}$ deficiency in pear seedlings reduced the activity of nitrate reductase enzyme in the roots and leaves; reduced the plant height, number of leaves and leaf area; and increased the rootto-shoot ratio (Chen et al., 2018).

Lack of $\mathrm{P}$ in the root environment only reduced the shoot weight and increased the SLW in BA seedlings. In leaves, the process of photosynthesis and carbohydrate distribution is strongly influenced by the concentration of mineral $\mathrm{P}$ in the stroma of chloroplasts and the $\mathrm{P}$ distribution between the chloroplasts and the cytoplasm. In the absence of $\mathrm{P}$, photosynthesis is almost completely stopped, and the zones and the rate of cell division in the leaves, and consequently their areas, are greatly reduced (Marschner, 2011).

\section{Morphological traits of the roots}

Lack of $\mathrm{N}$ in the root environment reduced the length, surface area, specific length and the fresh and dry weights of roots in BA seedlings (Figure 7), while under these conditions, the root diameter and RWR remained unchanged. In the AL seedlings, under $\mathrm{N}$-deficient condition, only the RWR increased and changes in other traits were not significant (Figure 3).

Lack of $\mathrm{P}$ in the nutrient solution decreased the root length, surface area and fresh weight and increased the root diameter in the BA seedlings, while the SRL, RWR and root dry weight of these seedlings were not affected. In the AL seedlings, the P deficiency increased the diameter and decreased the SRL but the other traits were not affected (Figure 3).

In the BA seedlings, the lack of $\mathrm{K}$ in the nutrient solution only reduced the root length and had no effect on the other traits. However, in the AL seedlings, K deficiency decreased only the SRL. These results showed that the least change in the root traits of both rootstocks occurred in the K-deficient condition (Figure 3).

The difference in the response of the two rootstocks to mineral nutrient-deficient conditions indicates the different response mechanisms of the two genotypes to the stress caused by deficiency of these elements. Small changes in most root traits of the AL seedlings under nutrient deficiency conditions indicate a higher tolerance of the AL seedling roots, compared to the BA seedling roots, or lower need for these three nutrients in this genotype.

Although many researchers believe that one of the root responses in the P-deficient condition is an increase in length ( $\mathrm{Wu}$ et al., 2005; Mei et al., 2011; Trubat et al., 2012) (due to the increase in cell division in the meristematic region), SRL (Mei et al., 2011), root clusters and root hairs (Yan et al., 2004), the results of this study show that the lack of $\mathrm{P}$ in the root environment not only did not increase the root length in the AL seedlings but also significantly reduced the root length in the BA seedlings. In the P-deficient condition, due to the role of this element in cell division, shoot growth is reduced; also, due to the transfer of carbohydrates, especially sucrose, to the roots, usually, in these plants root cell division and root growth increase (Marschner, 2011). However, in this study, the absence of $\mathrm{P}$ in the root environment had no effect on the vegetative traits of both rootstocks' shoots, especially the AL seedlings (Figure 1); therefore, it can be expected that carbohydrates are not transferred to the root and then do not increase the root growth.

Although, in the BA seedlings, all root morphological traits were affected by $\mathrm{N}$ deficiency, the concentration of this element in the shoots of these seedlings was about $43.9 \%$ lower than in control plants. In the AL seedlings, the reduction of shoot $\mathrm{N}$ concentration was about $31 \%$, while none of the root morphological traits were affected by $\mathrm{N}$ deficiency. The AL seedlings may respond to these conditions by altering the biochemical or physiological characteristics of the roots. A significant increase in the RWR of both genotypes in N-deficient conditions can result in a significant reduction in the shoot dry weight of the BA and AL seedlings (62.5\% and $28.6 \%$, respectively, compared to the control) under these conditions. In confirmation of these results, other researchers have observed that $\mathrm{N}$ deficiency increased branching of the root system but had no effect on the biomass of the root system (Trubat et al., 2012).

\section{Chlorophyll and SPAD}

In the BA seedlings, the lack of $\mathrm{N}$ and $\mathrm{P}$ caused a significant reduction in leaf greenness index, but the lack of $\mathrm{K}$ had no effect on this trait. In the AL seedlings, $\mathrm{N}$-, P- and K-deficient conditions significantly reduced the leaf greenness index (Figure 4A).

The results also showed that the concentrations of chlorophyll $a$, chlorophyll $b$ and total chlorophyll in the leaves of the two genotypes were significantly different. In the BA genotype, under $\mathrm{N}$-deficient conditions, chlorophyll $a$, chlorophyll $b$ and total chlorophyll concentrations decreased by $50 \%, 41 \%$ and $48 \%$, respectively, compared to the optimal condition, while in the AL seedlings, the concentration of only chlorophyll $a$ showed a significant reduction (Figure 4B-4D). In the P-deficient condition, the concentrations of chlorophyll $a$, chlorophyll $b$ and total chlorophyll in the BA seedlings showed a sharp decrease compared to the control $(39.6 \%, 38.2 \%$ and $39.4 \%$, respectively), but in the same conditions, these traits did not change significantly in the AL seedlings. K-deficient conditions significantly reduced the concentrations of chlorophyll $a$, chlorophyll $b$ and total chlorophyll in the BA seedlings and reduced the concentrations of chlorophyll $a$ and total chlorophyll in the AL seedlings. Although the lack of $\mathrm{N}$ in the nutrient solution reduced the chlorophyll $a / b$ ratio in both rootstocks, $\mathrm{P}$ and $\mathrm{K}$ deficiencies did not affect this index in both (Figure 4E). Although in the P-deficient condition, 

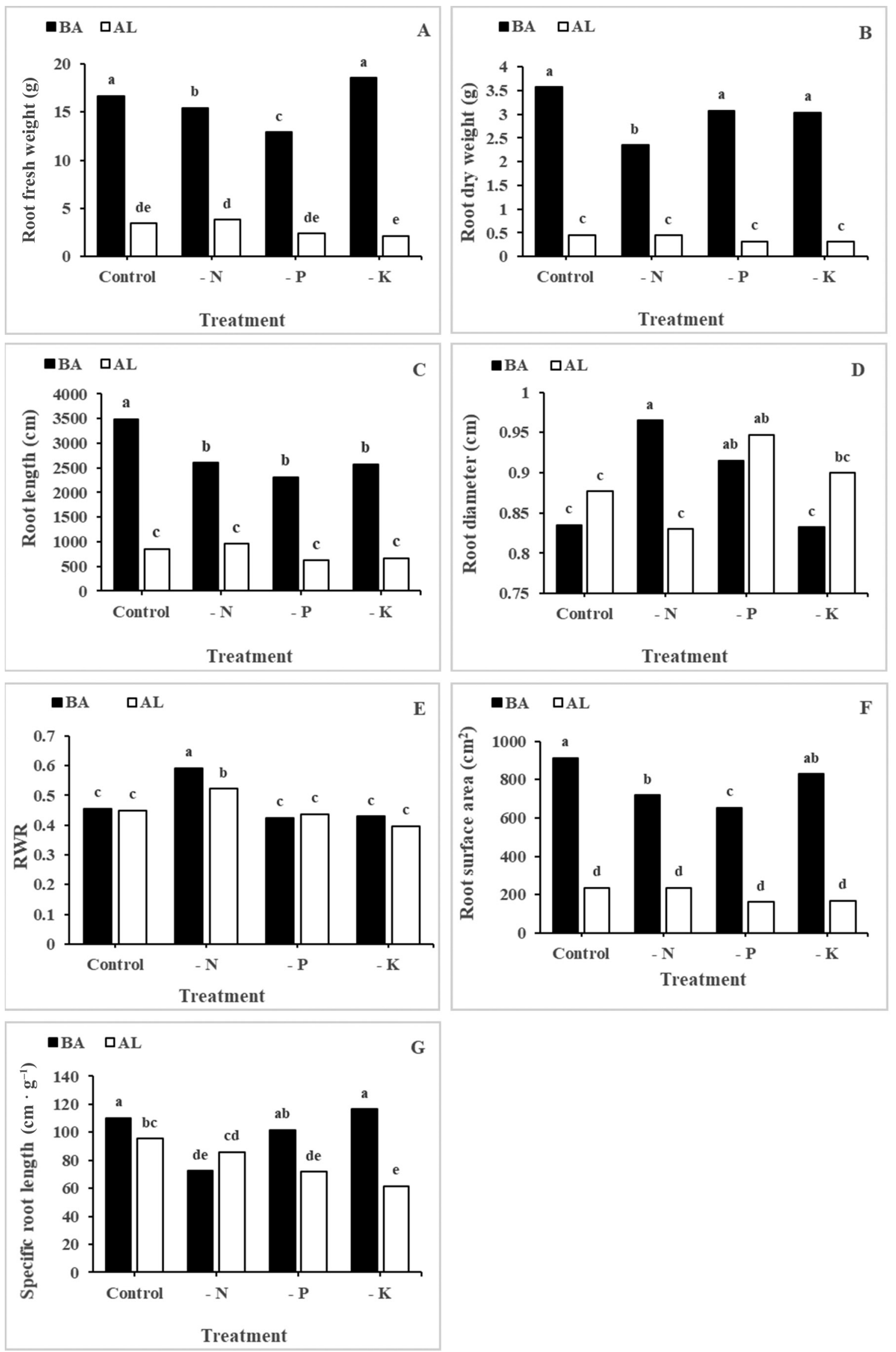

Figure 3. Effects of nutrient deficiency on the root morphological traits of the BA and AL seedlings. Different letters indicate statistically significant difference between means $(p<0.05) .-\mathrm{N},-\mathrm{P}$ and $-\mathrm{K}$ indicate media without $\mathrm{N}, \mathrm{P}$ and $\mathrm{K}$, respectively. AL, Alook (Prunus scoparia L.); BA, bitter almond (Prunus dulcis L.). 

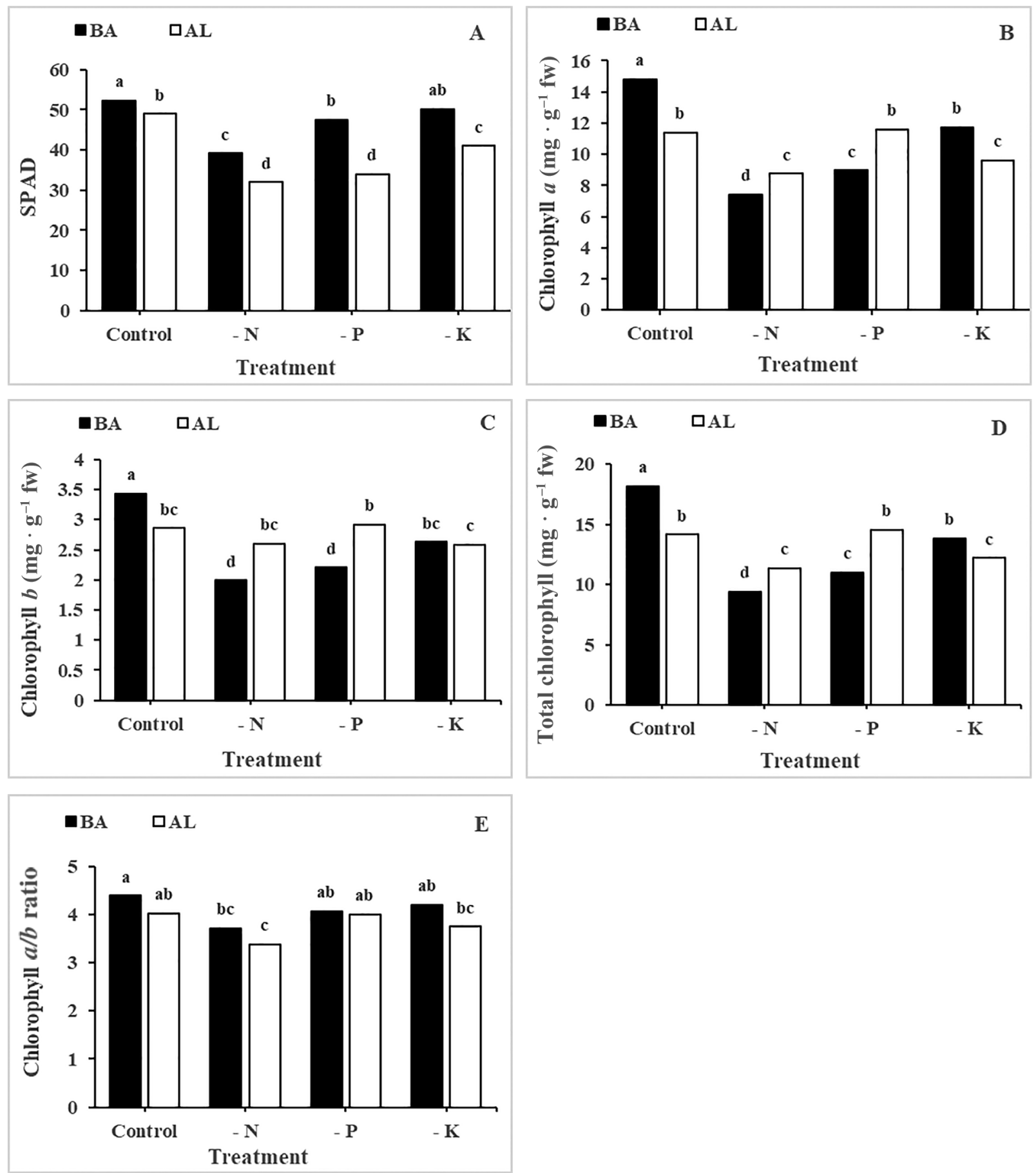

Figure 4. Effects of nutrient deficiency on $\operatorname{SPAD}$, chlorophyll $a$, chlorophyll $b$, total chlorophyll and chlorophyll $a / b$ ratio of the leaves of the BA and AL seedlings. Different letters indicate statistically significant difference between means $(p<0.05)$. $-\mathrm{N},-\mathrm{P}$ and $-\mathrm{K}$ indicate media without N, P and $\mathrm{K}$, respectively. AL, Alook (Prunus scoparia L.); BA, bitter almond (Prunus dulcis L.); fw, fresh weight.

leaf development is greatly reduced, the concentration of chlorophyll per unit area increases, and thus the leaves are dark green (Marschner, 2011); however, in this study, in the absence of $\mathrm{P}$, the leaf greenness index in both rootstocks and the concentration of chlorophyll $a$, chlorophyll $b$ and total chlorophyll in the leaves of the BA seedlings decreased, and the leaves became pale green. This can be attributed to the lack of leaf area reduction in these plants (Figure 2B). A decrease in total chlorophyll content and chlorophyll $a / b$ ratio due to $\mathrm{K}$ deficiency in plants has been previously reported (Hu et al., 2017). The results showed that in the BA seedlings, the absence of $\mathrm{N}, \mathrm{P}$ and $\mathrm{K}$ can significantly reduce the leaf chlorophyll, while in the AL seedlings, a significant reduction in chlorophyll concentration occurred in the absence of $\mathrm{N}$ and $\mathrm{K}$, and $\mathrm{P}$ deficiencies had no effect on these traits. In 
confirmation of our results, other studies showed that $\mathrm{K}$ stimulates chlorophyll synthesis and $\mathrm{K}$ deficiency inhibits its synthesis by increasing the concentration of ethylene and abscisic acid (Lawanson et al., 1977). On the other hand, K-deficient conditions cause morphological and structural changes in chloroplasts and thus reduce the leaf's photosynthetic capacity (Zhao et al., 2001; Shao et al., 2014). In addition, leaf chlorosis due to $\mathrm{K}$ deficiency can be due to oxidative degradation of chloroplasts and chlorophyll molecules due to increased production of oxygen free radicals (ROS) (Cakmak, 2005). Leaf chlorosis in the absence of $\mathrm{N}$ and $\mathrm{P}$ can be directly related to the lack of these elements in the structure of the chlorophyll molecule or indirectly due to the reduced absorption of other elements such as Fe, Mn and $\mathrm{Mg}$ (Taiz and Zeiger, 2010; Chen et al., 2018; Tu et al., 2018). In confirmation of this, Figure $1 \mathrm{E}$ shows that the concentration of shoot $\mathrm{Mg}$ in the BA seedlings was $44 \%$ and $52 \%$ lower in $\mathrm{N}$ and $\mathrm{P}$ deficiencies, respectively, than in the control plants. Although the change in the leaf greenness and chlorophyll content of both rootstocks was similar to the changes in $\mathrm{N}$ and K-deficient conditions, in the P-deficient condition, in the AL seedlings, only the leaf greenness decreased and the other traits showed no change. This indicates that the AL seedlings are more tolerant to $\mathrm{P}$ deficiency in terms of changes in photosynthetic pigment status.

\section{Chlorophyll florescence parameters}

In the BA seedlings, the lack of $\mathrm{P}$ and $\mathrm{K}$ caused $\mathrm{a}$ significant increase in $F_{0}$ compared to the optimal condition, but in the AL seedlings, the lack of $\mathrm{P}$ and $\mathrm{N}$ caused a significant decrease in this trait. In the BA seedlings the lack of $\mathrm{N}, \mathrm{P}$ and $\mathrm{K}$ had no significant effect on the $F_{\mathrm{m}}$, but in the AL seedlings, the lack of $\mathrm{P}$ and $\mathrm{N}$ significantly reduced the $F_{\mathrm{m}}$. On the other hand, the highest reduction of $F_{0}$ and $F_{\mathrm{m}}$ was observed in the P-deficient condition in the AL seedlings. The $F_{\mathrm{v}}$ of the BA seedlings was affected by only $\mathrm{K}$ deficiency compared to the control treatment, but in the AL seedlings, $\mathrm{N}, \mathrm{P}$ and $\mathrm{K}$ deficiencies decreased $F_{\mathrm{v}}$ by $27.4 \%, 34.3 \%$ and $9.7 \%$, respectively. The $F_{\mathrm{v}} / F_{\mathrm{m}}$ ratio was significantly higher only under P deficiency in the AL seedlings than in the control treatment; moreover, the absence of $\mathrm{N}, \mathrm{P}$ and $\mathrm{K}$ had no effect on this ratio in the BA seedlings, while the absence of $\mathrm{N}$ and $\mathrm{K}$ had no effect on this ratio in the AL seedlings. The $F_{\mathrm{v}} / F_{0}$ ratio in the BA seedlings was not affected by the lack of these three elements, while in the AL seedlings, the deficiency of $\mathrm{N}$ and $\mathrm{K}$ reduced this index by $14.8 \%$ and $22.7 \%$, respectively (Figure $5 \mathrm{~A}-5 \mathrm{E}$ ).

The significant difference between $F_{0}$ and $F_{\mathrm{m}}$ in the $\mathrm{BA}$ and AL seedlings in the control treatment indicates the differences in the function of the leaf light system of two genotypes. Evaluation of chlorophyll fluorescence parameters can provide accurate information about the status of the apparatus and components of the plant photosynthetic system, especially photosystem II (PS II) (Maxwell and Johnson, 2000). Increased $F_{0}$ can indicate the destruction of the reaction centre in PS II and the destruction of the structure and pigments of this photosystem under stress (nutrient deficiency). Damage to the electron transfer chain in PS II can be due to a decrease in the capacity of quinone A (QA) and its lack of complete oxidation due to the slow rate of electron transfer along the path of PS II and the total inactivation of PS II (Maxwell and Johnson, 2000). Increase in the $F_{0}$ and decrease in the $F_{m}$ is the sign of disruption of the activity of PS II. The decrease in $F_{\mathrm{m}}$ may be related to a decrease in the activity of the waterdegrading enzyme complex as well as the electron transfer cycle in or around PS II. When the electron acceptor (quinone) in PS II is in the reduced state, the performance of chlorophyll fluorescence is high and therefore the amount of variable fluorescence $F_{\mathrm{v}}$ is also high. However, when the electron acceptor is in the oxidised state, the amount of chlorophyll fluorescence is low, in which case, the $F_{\mathrm{v}}$ decreases (Maxwell and Johnson, 2000). Any environmental stress can reduce $F_{\mathrm{v}}$ because stress prevents light oxidation in PS II. Since $F_{\mathrm{v}}$ indicates complete reduction of the electron acceptor, it can be concluded that the decrease in the concentration of $\mathrm{N}, \mathrm{P}$ and $\mathrm{K}$ in the AL seedlings disturbs the electron transfer cycle of PS II and causes a response.

However, the difference in the changes in $F_{0}, F_{\mathrm{m}}$ and $F_{\mathrm{v}}$ in response to nutrient deficiency between the two genotypes shows the difference in the function of the light reaction centres in their leaf chloroplasts, and this trend causes changes in the $F_{0} / F_{\mathrm{m}}$ ratio, while $F_{\mathrm{v}} / F_{\mathrm{m}}$ showed no significant difference. The $F_{\mathrm{v}} / F_{\mathrm{m}}$ ratio is the main indicator for examining photoinhibition or damage to PS II (Bednarz et al., 1998; Li et al., 2011). However, in this study, due to the almost similar trend of changes in the two indices $F_{\mathrm{v}}$ and $F_{\mathrm{m}}$, no significant difference was observed in this ratio. In two cultivars of corn susceptible to $\mathrm{K}$ deficiency, the $F_{\mathrm{v}} / F_{\mathrm{m}}$ ratio decreased with $\mathrm{K}$ deficiency due to the decrease in $F_{\mathrm{m}}$, and it was observed that in these two cultivars and under $\mathrm{K}$ deficiency stress, the reaction centres of PS II and the electron transfer chain stopped functioning, which resulted in severe peroxidation of the cell membrane due to the accumulation of oxygen-derived free radicals such as peroxide $\left(\mathrm{O}_{2}{ }^{-}\right)$and hydrogen peroxide $\left(\mathrm{H}_{2} \mathrm{O}_{2}\right)$ (Du et al., 2019). Comparison of the response of sensitive and tolerant citrus rootstocks to nutrient deficiency conditions also showed that in moderately tolerant rootstocks, the $F_{\mathrm{v}} / F_{\mathrm{m}}$ ratio was higher than in susceptible genotypes, which indicated that in deficiency-tolerant genotypes, nutrients cause less disruption to the photosynthetic process of these rootstocks (Oustric et al., 2019).

\section{CONCLUSIONS}

Responses to nutrient deficiency may differ among different plant genotypes. We found that there is a negative interaction between the changes in $\mathrm{N}$ and 

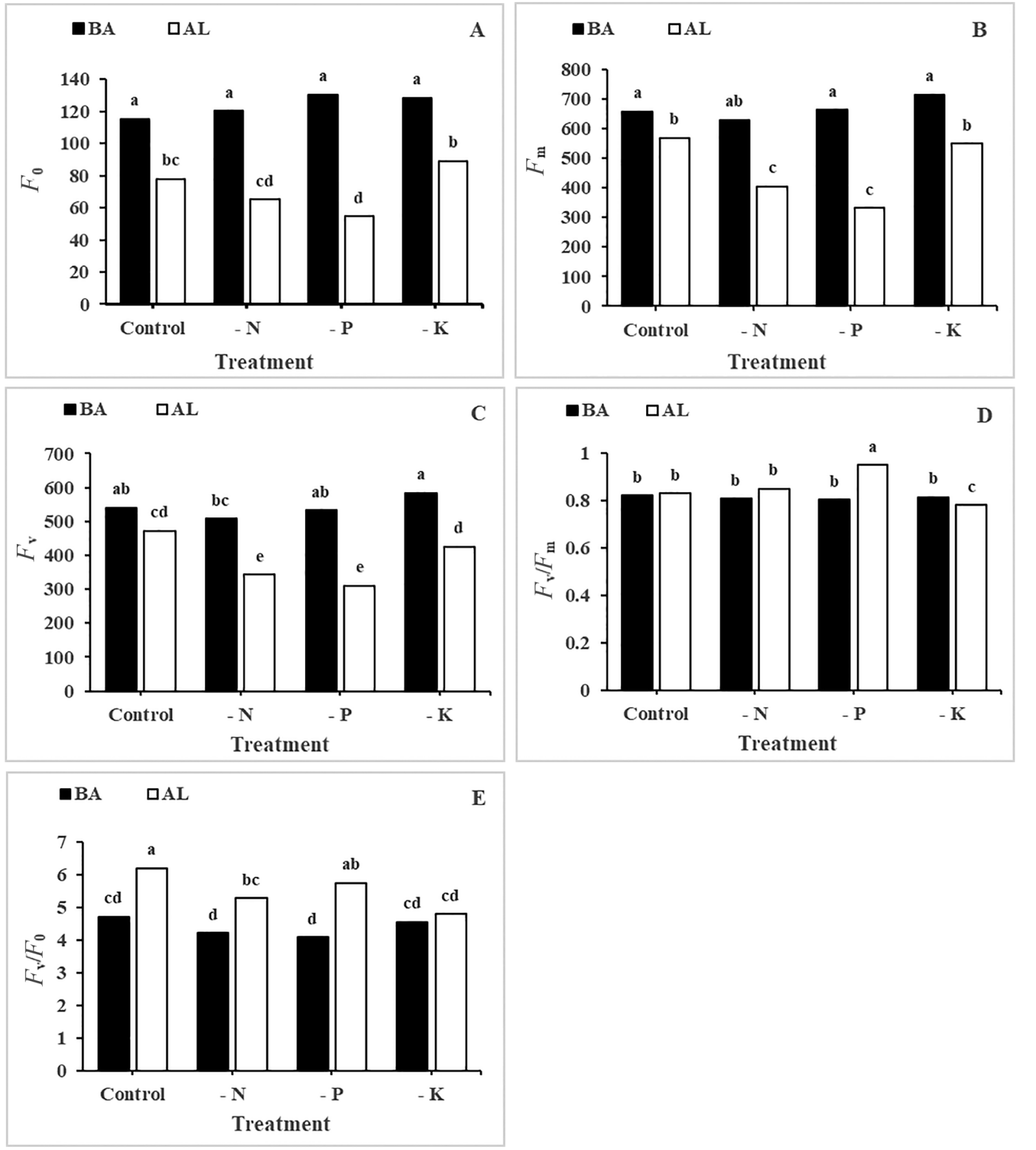

Figure 5. Effects of nutrient deficiency on the chlorophyll fluorescence parameters of the leaves of BA and AL seedlings. Different letters indicate statistically significant difference between means $(p<0.05)$. $-\mathrm{N},-\mathrm{P}$ and $-\mathrm{K}$ indicate media without $\mathrm{N}, \mathrm{P}$ and $\mathrm{K}$, respectively. $F_{0}$, initial fluorescence; $F_{\mathrm{m}}$, maximum fluorescence; $F_{\mathrm{v}}$, variable fluorescence; AL, Alook (Prunus scoparia L.); BA, bitter almond (Prunus dulcis L.).

$\mathrm{K}$ concentrations and a positive interaction between $\mathrm{N}$ and $\mathrm{Ca}$ in the shoots of both rootstocks, so that as the $\mathrm{N}$ concentration decreases, the concentration of $\mathrm{K}$ increases and $\mathrm{Ca}$ decreases. The concentrations of $\mathrm{N}$ and $\mathrm{K}$ in the shoots of the BA seedlings were significantly lower than those in the shoots of the AL seedlings in all of the treatments, but in terms of $\mathrm{P}$, it depends on the nutritional status of the plant. The condition of $\mathrm{P}$ deficiency did not affect the morphological traits of the shoot in both the genotypes, which indicates that the demand for $\mathrm{P}$ was low in the two rootstocks. $\mathrm{K}$ deficiency in both rootstocks had the least effect on shoot and root biomass, which indicate that both rootstocks undertake luxury consumption of $\mathrm{K}$ and can maintain their optimal growth even at very low concentrations of $\mathrm{K}$. We found that AL seedlings have the ability to maintain $\mathrm{N}$ concentration in their shoots or absorb more of this element, compared to the BA 


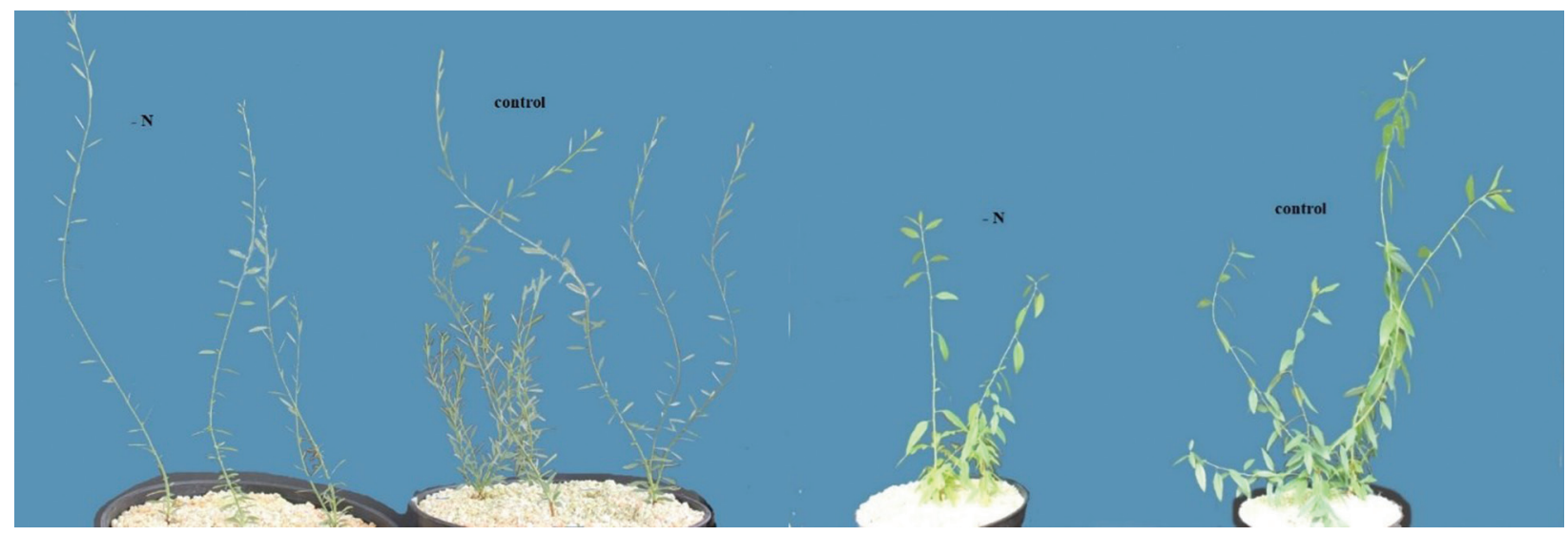

Figure 6. Comparison of plant height of Alook (Prunus scoparia L.) (left) and bitter almond (Prunus dulcis L.) (right) seedlings under nitrogen deficiency $(-\mathrm{N})$ treatment.
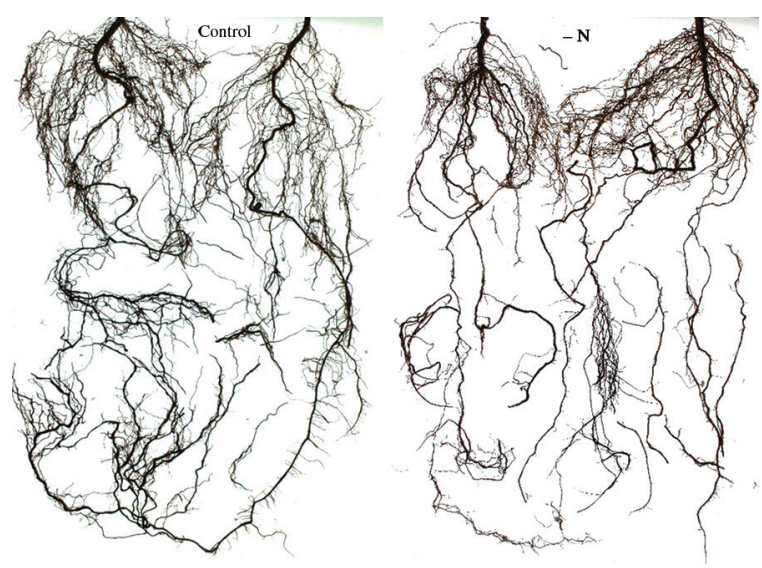

Figure 7. Comparison of the root system architectures of bitter almond (Prunus dulcis L.) seedlings in control (left) and N-deficiency (right) treatment.

seedlings, even under nutrient stress conditions. The difference in the response of the two rootstocks to the mineral nutrient deficiency conditions indicates the different mechanisms of the two genotypes in their responses to the stress caused by the deficiency of these elements. No changes in most of the root traits of the AL seedlings under nutrient deficiency conditions indicates either a higher tolerance of the AL root compared to the BA root or lower need for these three nutrients in this genotype. Our results indicate that the AL seedlings are more tolerant to $\mathrm{P}$ deficiency conditions in terms of changes in photosynthetic pigment status. Decreases in the concentrations of $\mathrm{N}, \mathrm{P}$ and $\mathrm{K}$ in the $\mathrm{AL}$ seedlings disturbed the electron transfer cycle of PS II and caused a response. The results of this study showed that compared to the BA rootstock, the characteristics of $P$. scoparia seedlings were less affected by deficiencies of these three elements, and therefore, $P$. scoparia rootstock is preferred to BA rootstock for infertile soils. The higher tolerance mechanism of $P$. scoparia and its comparison with conventional clonal rootstocks require further investigation.

\section{FUNDING}

This work received no external funding.

\section{CONFLICT OF INTEREST}

The authors declare no conflict of interest.

\section{REFERENCES}

Basile, B., Reidel, E., Weinbaum, S., and Dejong, T. (2003). Leaf potassium concentration, $\mathrm{CO}_{2}$ exchange and light interception in almond trees (Prunus dulcis (Mill) DA Webb). Scientia Horticulturae, 98, 185-194.

Bednarz, C., Oosterhuis, D., And Evans, R. (1998). Leaf photosynthesis and carbon isotope discrimination of cotton in response to potassium deficiency. Environmental and Experimental Botany, 39, 131-139.

Bremner, J. M. (1996). Nitrogen-total. Methods of Soil Analysis: Part 3 Chemical Methods, 5, 1085-1121.

CAKMAK, I. (2005). The role of potassium in alleviating detrimental effects of abiotic stresses in plants. Journal of Plant Nutrition and Soil Science, 168, $521-530$

Chen, G., Wang, L., Fabrice, M. R., Tian, Y., Qi, K., Chen, Q., CaO, P., Wang, P., Zhang, S., and Wu, J. (2018). Physiological and nutritional responses of pear seedlings to nitrate concentrations. Frontiers in Plant Science, 9, 1679, doi: 10.3389/fpls.2018.01679.

Desnos, T. (2008). Root branching responses to phosphate and nitrate. Current Opinion in Plant Biology, 11, 82-87.

Du, Q., ZhaO, X., Xia, L., Jiang, C., Wang, X., Han, Y., Wang, J., AND Yu, H. (2019). Effects of potassium deficiency on photosynthesis, chloroplast ultrastructure, ROS, and antioxidant activities in maize (Zea mays L.) Journal of Integrative Agriculture, 18(2), 395-406.

Gharaghani, A., And Eshghi, S. (2015). Prunus scoparia, a potentially multi-purpose wild almond species in Iran. Acta Horticulturae, 1074, 67-72. 
Gradziel, T., Martínez-Gómez, P., Dicenta, F., And Kester, D. (2001). The utilization of related Prunus species for almond variety improvement. Journal of the American Pomological Society, 55, 100.

Hoagland, D. R., And Arnon, D. I. (1950). The waterculture method for growing plants without soil. Circular California Agricultural Experiment Station, 347, 32.

Hu, W., Coomer, T. D., LoKa, D. A., Oosterhuis, D. M., AND Zhou, Z. (2017). Potassium deficiency affects the carbon-nitrogen balance in cotton leaves. Plant Physiology and Biochemistry, 115, 408-417.

JACKSON, M. L. (2005). Soil chemical analysis: Advanced course. Madison, USA: UW-Madison Libraries Parallel Press.

Lawanson, A., Otusanya, O., And Akomolede, D. (1977). Mechanism of potassium deficiency-induced retardation of chlorophyll biosynthesis in Zea mays. Experientia, 33, 1145-1146.

Leghari, S. J., Wahocho, N. A., Laghari, G. M., Hafeezlaghari, A., Mustafabhabhan, G., Hussaintalpur, K., Bhutto, T. A., Wahocho, S. A., AND LASHARI, A. A. (2016). Role of nitrogen for plant growth and development: A review. Advances in Environmental Biology, 10, 209-219.

Li, X.-T., CaO, P., Wang, X.-G., CaO, M.-J., and Yu, H.-Q. (2011). Comparison of gas exchange and chlorophyll fluorescence of low-potassium-tolerant and-sensitive soybean [Glycine max (L.) Merr.] cultivars under lowpotassium condition. Photosynthetica, 49, 633-636.

López-Bucio, J., Cruz-Ramirez, A., AND HerreraEstrella, L. (2003). The role of nutrient availability in regulating root architecture. Current Opinion in Plant Biology, 6, 280-287.

Madam, B., Rahemi, M., Mousavi, A., and MartínezGómez, P. (2011). Evaluation of the behavior of native Iranian almond species as rootstocks. Journal of Nuts, 2, 29-34.

MARSCHNER, H. (2011). Marschner's mineral nutrition of higher plants. Waltham, USA: Academic Press.

Maxwell, K., And Johnson, G. N. (2000). Chlorophyll fluorescence - A practical guide. Journal of Experimental Botany, 51, 659-668.

Mei, L., Sheng, O., Peng, S.-A., Zhou, G.-F., Wei, Q.-J., AND LI, Q.-H. (2011). Growth, root morphology and boron uptake by citrus rootstock seedlings differing in boron-deficiency responses. Scientia horticulturae, $129,426-432$.

Mozaffarian, V. (1996). Encyclopedia of Iranian plants. Tehran, Iran: Farhang Moaser Publication, 671.

Oustric, J., Morillon, R., Luro, F., Herbette, S., Martin, P., Giannettini, J., Berti, L., and Santini, J. (2019). Nutrient deficiency tolerance in citrus is dependent on genotype or ploidy level. Frontiers in Plant Science, 10, 127, doi: 10.3389/fpls.2019.00127.
Shao, Q., Wang, H., Guo, H., Zhou, A., Huang, Y., Sun, Y., AND Li, M. (2014). Effects of shade treatments on photosynthetic characteristics, chloroplast ultrastructure, and physiology of Anoectochilus roxburghii. PloS ONE, 9, e85996, doi: 10.1371/ journal.pone.0085996.

Shibli, R., Jaradat, A., Ajlouni, M., Aljanabi, S., And KHAWALDEH, W. (1998). In vitro multiplication of bitter almond (Amygdalus communis L.). Damascus University Journal of Agricultural Sciences, 14, 110-120.

Shibli, R., Shatnawi, M., Ajlouni, M., Jaradat, A., And AdHAm, Y. (1999). Slow growth in vitro conservation of bitter almond (Amygdalus communis L.). Advances in Horticultural Science, 13, 133-134.

TAiz, L., And ZeIger, E. (2010). Plant physiology. Sunderland, MA, USA: Sinauer Associates, 464.

Trubat, R., Cortina, J., And Vilagrosa, A. (2012). Root architecture and hydraulic conductance in nutrient deprived Pistacia lentiscus L. seedlings. Oecologia, 170, 899-908.

Tu, P., Deng, L., Li, J., Zhang, C., He, S., Chen, J., Cheng, F., And Ji, J. (2018). Effect of phosphorus on $\mathrm{N}, \mathrm{P}, \mathrm{K}, \mathrm{Mg}$ accumulation and plant growth of different citrus rootstocks. Applied Ecology and Environmental Research, 16, 819-836.

WARREN, C. (2008). Rapid measurement of chlorophylls with a microplate reader. Journal of Plant Nutrition, 31, 1321-1332.

Wu, C., Wei, X., Sun, H. L., And Wang, Z. Q. (2005). Phosphate availability alters lateral root anatomy and root architecture of Fraxinus mandshurica Rupr. seedlings. Journal of Integrative Plant Biology, 47, 292-301.

Yan, X., Liao, H., Beebe, S. E., Blair, M. W., and LYNCH, J. P. (2004). QTL mapping of root hair and acid exudation traits and their relationship to phosphorus uptake in common bean. Plant and Soil, $265,17-29$.

Zambrosi, F. C. B., Mattos, D., Boaretto, R. M., Quaggio, J. A., Muraoka, T., and Syvertsen, J. P. (2012). Contribution of phosphorus (32 P) absorption and remobilization for citrus growth. Plant and Soil, $355,353-362$.

Zarate-Valdez, J. L., Muhammad, S., SaA, S., Lampinen, B. D., AND Brown, P. H. (2015). Light interception, leaf nitrogen and yield prediction in almonds: A case study. European Journal of Agronomy, 66, 1-7.

Zhao, D., Oosterhuis, D., And Bednarz, C. (2001). Influence of potassium deficiency on photosynthesis, chlorophyll content, and chloroplast ultrastructure of cotton plants. Photosynthetica, 39, 103-109.

Received: January 30, 2021; accepted: July 6, 2021 